\title{
Como me tornei \#dotorainspiração e o brinco de Ewá
}

\author{
Giovana Xavier' (iD 0000-0002-6118-3889 \\ 'Universidade Federal do Rio de Janeiro, Faculdade de Educação, Rio de Janeiro, RJ, \\ Brasil. 22290-240-ppge@fe.ufri.br
}

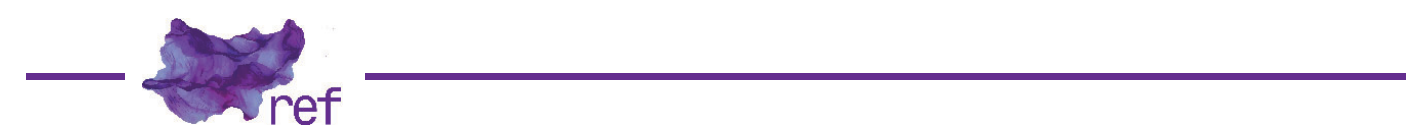

Resumo: O objetivo deste ensaio é discutir as interfaces entre intelectualidade acadêmica e pública em diálogo com feministas negras e decoloniais. Levando em conta a produção de uma "narrativa na primeira pessoa", discuto minha própria trajetória como professora universitária, destacando a relevância da construção de projetos científicos baseados na autoimagem de mulheres negras como intelectuais. Em atenção à crítica de Ochy Curiel sobre a imposição de renúncia da "vida social" para alcançar uma carreira bem-sucedida, trago para primeiro plano a importância de discutir o papel da subjetividade e da produção de conhecimentos autodefinidos na vida de mulheres negras. Por fim, reflito sobre os dilemas e possibilidades colocados para a intelectualidade de mulheres negras por meio de experiências vivenciadas nos últimos quatro anos, entre elas a criação do Grupo Intelectuais Negras UFRJ, a participação em programas televisivos e o posto de colunista no Nexo Jornal.

Palavras-chave: intelectual negra; autodefinição; narrativa na primeira pessoa; feminismos interseccionais.

\section{How I became \#dotorainspiração and the Ewá's Earring}

Abstract: The aim of this article is to discuss the interfaces between academic and public intellectuality in dialogue with black and decolonial feminists. Taking into account the production of a "first person narrative", I discuss my own trajectory as a university professor, highlighting the relevance of the construction of scientific projects based on the self-image of black women as intellectuals. In consideration of Ochy Curiel's critique of the renunciation of "social life" to achieve a successful career, I bring to the fore the importance of discussing the role of subjectivity and the production of self-defined knowledge in the lives of black women. Finally, I reflect on the dilemmas and possibilities posed for the intellectuality of black women through experiences lived in the last four years, among them the creation of Black Intellectuals Group, participation in television programs and the post of columnist in Nexo Newspaper.

Keywords: Black Intelectual; Selfdefinition; First Person Narrative; Interseccional Feminisms.

Em maio de 2013, no dia seguinte à minha aprovação no concurso para professora efetiva de Didática Especial e Prática de Ensino de História da Faculdade de Educação da UFRJ, fui à Casa Rui Barbosa para rever amigos e acompanhar o seminário "Instituições Nefandas: o fim da escravidão e da servidão no Brasil, Estados Unidos e Rússia". Embora não inédito em minha trajetória, incomodou-me profundamente o fato de o evento contar com apenas uma pesquisadora negra na programação, sobretudo, levando em consideração o fato de historiadoras brancas apresentarem seus trabalhos e conclusões sobre temas sensíveis como o infanticídio entre mães escravizadas no século XVIII. Ao apresentar seu trabalho sobre maternidade de mulheres escravizadas e infanticídio, a historiadora repetiu inúmeras vezes a expressão "especificidade de ser mulher negra". Na dúvida do que isso queria exatamente dizer, perguntei. Não obtive resposta. Essa situação colocou-me diante de duas questões que passariam a impactar os rumos de meu percurso acadêmico: o que é conhecimento? Quem está autorizado a produzi-lo?

Em ambientes acadêmicos, quando feitas por pessoas negras, essas indagações costumam ser respondidas com desqualificações baseadas numa hierarquia entre ciência e ativismo, 
arrematada pelos clássicos e chulos argumentos do "mimimi" e do "racismo reverso". No caso de mulheres negras, os estereótipos da agressividade e do barraco, personificados na imagem da "treteira", são também acionados. Esse encadeamento relaciona-se a representações produzidas ao longo da história da escravidão e do pós-abolição, nas quais a representação predominante da mulher negra é a de realizadora do trabalho abnegado, uma vez que a abnegação não pressupõe formulação de opiniões próprias e críticas acadêmicas deste grupo racial que assumem esses lugares e são lidas por meio das "imagens controladas" descritas acima (Patricia COLLINS, 2019, p. 3).

Dados do Conselho Nacional de Desenvolvimento Científico e Tecnológico sobre a "participação de negras e negros no sistema científico" oportunizam o aprofundamento desta análise, deslocando-nos do terreno dos achismos e focando na raiz do problema: o machismo e o racismo na distribuição do conhecimento acadêmico. Considerando informações sobre bolsistas de produtividade científica em 2015, "os pardos e as pardas representam cerca de $8 \%$ e $6 \%$ respectivamente, enquanto os pretos e pretas somam aproximadamente 1,2\% e 0,8\%" (Betina LIMA; Maria Lúcia BRAGA; Isabel TAVARES, 2015, p. 28).

Esse contexto de interação entre "eixos de opressão específicos" (Kimberlé CRENSHAW, 1991) levou-me a buscar a escrita de um texto que abordasse a situação, livre das formalidades acadêmicas, sem, contudo, deixar de ser uma narrativa acadêmica. "O dia em que Rui Barbosa sorriu (ou chorou?)" marcou minha estreia como autora do blog Preta 'Dotora' na primeira pessoa:

[...] Maio, mês das mães, mês das noivas, mês do trabalhador. O mês cinco tem se tornado cada vez menos o mês da abolição da escravidão, o mês de aniversário da lei Áurea. Isso tem a ver com um monte de coisas. Dentre elas, o fortalecimento do dia 20 de novembro (morte de Zumbi dos Palmares) como data para celebrar a história de resistência da população negra, a partir da ótica dos movimentos sociais negros. Uma crítica forte e profunda à ideia da Princesa Isabel como a redentora. À lei Áurea como dádiva. Esse debate do 13 de maio X 20 de novembro é dos bons, briga de gente grande. Um dia falaremos... O fato é que o episódio que quero narrar ocorreu no mês de maio. Um maio, não custa lembrar, sempre oportuno para discutir as implicações históricas do pós-abolição no tempo presente. Pois bem, recebi por e-mail a programação de um seminário dedicado a discutir a abolição em perspectiva comparada, articulando a experiência do Brasil à de outros países. Achei a programação muito boa, reunindo a fina flor da nossa historiografia. Meu interesse cresceu quando me dei conta de que havia uma mesa específica para discutir gênero e abolição. A primeira pessoa que vos fala foi tomada por um pensamento óbvio. Eu pesquiso mulheres negras no pós-abolição do Brasil e dos EUA, logo irei assistir. Convidei uma aluna que estuda o pós-abolição nos livros didáticos de História para ir comigo, que prontamente topou (confesso que ela chegou primeiro que eu. Quando se tem um filho pequeno, o simples ato de conseguir sair de casa é revolucionário, principalmente às 9 da matina!). Passada a saga matinal, finalmente cheguei. Vi vários rostos conhecidos, de pessoas queridas que vamos agregando às nossas vidas ao longo da trajetória acadêmica. Respirei, sentei, abri o computador. E quando comecei a prestar atenção na discussão percebi a "proeza" da boa e velha academia. Uma mesa sobre gênero e abolição composta exclusivamente por pessoas brancas, discutindo sobre experiências de mulheres negras. Como aprendi com minha mãe, as coisas sempre podem ficar piores. Olhei detalhadamente a composição do painel. Percebi que havia uma equidade de gênero (2 homens e 2 mulheres). Ufa, nós mamães nem sempre temos razão! Aí pessoal, cada dia que passa eu compreendo mais e mais minha amiga (ela não sabe que é minha amiga) do excelente blog "uma feminista cansada" (http:// www.feministacansada.com/). Dá uma preguiça esse negócio de ser "minoria política" e ter que toda hora ficar falando a mesma coisa. Com tantos problemas para enfrentar, ainda mais essa obrigação de educar as pessoas. "Não se preocupem, nós sabemos contar nossas histórias. Da próxima vez contem conosco!" Com as novas tecnologias em alta, tenho pensado em deixar esta mensagem gravada no meu celular. Quando chegar a minha vez de falar, bastará reproduzi-la. Ah! Os trabalhos apresentados traziam discussões muito boas, feitas por historiadores e historiadoras de altíssimo nível. Já que está na moda falar de alteridade, propusme o exercício de me imaginar participando de uma mesa sobre a história do holocausto com mais três colegas de profissão pretinhos da cor da noite e que não fossem judeus. De olhos bem fechados, a cena não veio. Não virá. A imaginação tem limites muito precisos de gênero, raça e classe. Essa mesa me remeteu a uma experiência dos meus tempos de doutoranda. Cursei uma disciplina sobre metodologia e teoria da história na qual a turma, dividida em grupos, tinha que apresentar seminários. Um dos grupos ficou com a história dos judeus, trabalhada a partir da famosa biografia do Primo Levi, que narra o cotidiano no campo de concentração de Auschwitz. Comoção total na sala. Semblantes cabisbaixos, olhos de ressaca, silêncio absoluto. Levantar ou não o dedo? Eis a questão. Pergunta simpática: por que não existe a mesma comoção com a história do tráfico de africanos para as Américas, em especial para o Brasil, onde desembarcaram aproximadamente quatro milhões de africanos? Tolinha eu! Mas a sorte é que sempre contamos com pessoas informadas, que podem nos ensinar o que desconhecemos. Foi com essa vibe que uma colega olhou no fundo dos meus olhos e disse com a mais sincera franqueza: "Se isso te interessa, estuda o assunto, faz teu seminário sobre isso", (isso = tráfico de seres humanos). 0 professor, também na vibe da ajuda, argumentava: "isso não é estudado porque não tem muitos 
negros aqui na universidade". Cansaço pouco é bobagem... rumo à exaustão! Voltando ao evento de maio, na hora que a discussão foi aberta à audiência, pedi que explicassem melhor o que chamavam de "especificidades de ser mulher negra". Fiquei sem resposta, mas pelo andar da carruagem até achei bom. Seguindo a lógica da minha mãe, de que as coisas sempre podem piorar, poderiam ter seguido o exemplo de minha colega de turma, respondendo: "já que isso te interessa, defina você as especificidades". Em alguns casos, o silêncio é uma vitória! Na lógica "quebro, mas não envergo", fiz um breve comentário sobre a mulher negra como a "prima pobre" da historiografia da escravidão e do pós-abolição, haja vista os pouquíssimos trabalhos disponíveis. Este comentário disparou um debate muito comum na História. Uma discussão sobre a necessidade de separar ativismo social da pesquisa como garantia de investigação séria e de qualidade. Como feminista negra, acho que pesquisa histórica é ativismo, é posicionalidade. É olhar, reconstituir e contar histórias na primeira pessoa, talvez porque, para mim, que sou 24h por dia uma mulher negra, esse seja um caminho inevitável. Com tudo isso lembrei de Rui Barbosa. Abolicionista convicto, ele rotineiramente ostentava uma camélia ("confissão de fé abolicionista") na lapela do paletó. Apreciador da natureza, conta-se que marcou o jardim da sua casa com um pé de camélia, situado debaixo da janela de seu quarto de dormir. Resta saber se Rui teria esbanjado sorrisos ou derramado lágrimas se tivesse ouvido as reflexões sobre gênero e abolição na terceira pessoa (Giovana XAVIER, 2014).

De certo, as questões apresentadas no texto podem ser exploradas em dimensões variadas, incluindo a redução de um problema estrutural à busca simplista de quem está com a razão (Francisco BOSCO, 2017). Mas o que interessa dimensionar é que a publicação e a alta repercussão do texto tornaram-se divisores de águas em minha carreira. Se em algum momento a ideia foi ter uma vida pacata de mãe, professora e pesquisadora, essas expectativas (que nunca existiram) foram totalmente contrariadas. Daquele dia em diante, iniciava-se uma das maiores ventanias de minha vida. A construção de uma identidade profissional marcada pela difícil articulação dos lugares de professora universitária e militante de movimentos sociais. Uma jornada desafiadora, inspirada pelo que Donna Haraway (1995) denomina crítica à "objetividade científica descorporificada" (p. 9). Há meses de completar uma década como docente de uma das maiores universidades do Brasil, miro o passado. E constato: todo meu trabalho acadêmico tem sido voltado para a construção de um projeto político acadêmico pautado em uma objetividade corporificada nos saberes e experiências de mulheres negras.

É dentro dessa perspectiva, a qual nomeio "ciência localizada", que se inserem tanto a história do blog, do perfil no Instagram e da coluna no Nexo Jornal, assim como as diferentes iniciativas que conduzo como professora universitária: o Grupo Intelectuais Negras (2014), a disciplina de graduação homônima (2015), o projeto de extensão Diálogos (2016), a gestão do Programa de Educação Tutorial Conexões de Saberes Diversidade (desde 2016). Em termos de fortalecimento de novas epistemologias, é importante pensar a junção de todos esses lugares de fala para além de questões de ego e vaidade. Na perspectiva do feminismo interseccional, essa multiplicidade refere-se à certeza de que mulheres negras possuem "um ponto de vista autodefinido e de grupo", norteador de suas ações (COLLINS, 1990 [2013], p. 3).

\section{Intelectual Negra: a transgressão de seguir uma "vida da mente"}

Nascida em uma família pobre, os estudos, desde cedo, apresentaram-se como um caminho para a transformação da nossa realidade. Essa percepção era alimentada por tia, mãe e avó que marcavam duro para que eu e meus primos tivéssemos o melhor desempenho na nossa escolarização. Ao mesmo tempo em que havia uma aposta coletiva na educação como possibilidade de ascensão social, a memória da escravidão (Martha ABREU et al., 2007) regulava as relações, sobretudo na criação das meninas. Éramos ensinadas, desde cedo, a lavar, passar e cozinhar. "Filha, você precisa aprender porque quando for trabalhar em uma casa de família terá de fazer estas tarefas muito bem feitas", palavras de minha avó. Essa relação antagônica entre o trabalho intelectual e o braçal é abordada por bell hooks (1995) no importante artigo "Intelectuais Negras":

[...] é o conceito ocidental sexista/racista de quem e o quê e um intelectual que elimina a possibilidade de nos lembrarmos de negras como representativas de uma vocação intelectual. Na verdade dentro do patriarcado capitalista com supremacia branca toda a cultura atua para negar às mulheres a oportunidade de seguir uma vida da mente torna o domínio intelectual um lugar interdito (1995, p. 468).

A negação da oportunidade de projetar uma "vida da mente" incide de forma específica nas trajetórias de mulheres negras, como vimos, historicamente representadas como portadoras de uma natureza agressiva, descontrolada, hipersexualizada ou na condição de trabalhadoras abnegadas. Essas interseções entre opressões de gênero, raça e classe fazem com que a carreira intelectual seja um horizonte muito distante para a maioria de nós. Como professora, já perdi a 
conta de quantas vezes ouvi estudantes negras relatando seus sentimentos de não identificação com a universidade, embora nutram a vontade de seguir estudando.

No primeiro dia de aula do curso Intelectuais Negras, peço que todas que se sintam à vontade coloquem em prática um dos principais conceitos do feminismo negro: a "autonomeação". Para se apresentar ao restante da turma, solicito que vocalizem "Eu sou uma intelectual negra por que...". Esse é um momento de muita emoção, com abraços, lágrimas, lenços de papel circulando pela sala. Por mais que brotem narrativas sobre avós e mães repletas de beleza, força e inteligência, a potência dessas mulheres vai perdendo espaço para "Mas professora...", "eu sou a primeira da família a entrar na universidade", "Minha mãe é empregada doméstica", "Não conheço meu pai", "Minha avó não sabe ler", "Não sei falar Inglês", "Tenho muita dificuldade de escrever", "Nunca viajei para fora", "Na minha casa não tem biblioteca", "Não consigo ler lá em casa porque tem muito barulho", "O professor disse que eu vou ser balconista".

Carece de observações mais profundas o fato de que muito do desejo de estudar se torna um grande peso, devido às expectativas familiares em torno do diploma, significado como patrimônio coletivo. Um símbolo de ascensão, análogo a uma espécie de carta de alforria para todos. Essa relação das famílias negras com parentes que acessam a universidade é uma forma importante de questionar a ideia hegemônica de meritocracia como resultado do esforço individual. Trajetórias de estudantes negros que acessaram, nos últimos anos, a universidade pública por meio das políticas de ação afirmativa falam mais sobre projetos familiares coletivos do que sobre heroísmo e superação.

Cada uma dessas frases das universitárias remete à minha infância de menina incompreendida. Tratada como rebelde por gostar de escrever, ler, expressar suas vontades. Atividades intelectuais que ligam ao desejo de cultivar tempo para mim mesma. Em um país patriarcal, com passado escravista, o conhecer-se não é um direito concedido a meninas negras. Nesse sentido, no decorrer de minha carreira, aprendi que qualquer movimento para a construção de epistemologias localizadas nos saberes de mulheres negras deve levar em conta nossas trajetórias afetivas, familiares, profissionais em suas formulações.

Se não temos a oportunidade de reinterpretar nossos passados colocando as lentes no sistema de opressão em que nos inserimos, acabamos por aceitar a "imagem dominante" de nós mesmas, além de sermos "paralisadas por um sentimento de desamparo" (Pauli MURRAY, 1987, p. 10). Considerando o feminismo negro como um projeto que parte do reconhecimento de mulheres negras como sujeitas políticas, cabe a nós a produção de conhecimento por meio de novos marcos que rompam com visões estáticas das categorias de gênero, raça, classe, sexualidade (Prathiba PARMAR, 2012) e que nos possibilitem 'pular fora' das estruturas e sistemas dados pelas autoridades e criar suas próprias estruturas (MURRAY, 1987, p. 134).

Foi a partir dessas percepções, aprimoradas pelas interlocuções com autoras feministas negras e do Sul Global, assim como na interação com mulheres negras ativistas e estudantes de diversas áreas, que nasceu o Grupo Intelectuais Negras UFRJ. Um projeto bem-sucedido de criação de nossas próprias estruturas dentro do sistema acadêmico, hegemonicamente baseado na supremacia branca, masculina e heteronormativa. Embora não seja meu objetivo narrar a história do Grupo neste texto, alguns aspectos parecem relevantes de serem discutidos.

O fato de um grupo de mulheres negras ocuparem o espaço acadêmico com o propósito de construírem sentidos de intelectualidade ligados às histórias suas e das antepassadas é de alta relevância para disputar narrativas e produzir novas perguntas e respostas sobre quem somos, nossos projetos e histórias. Nesse sentido, o investimento na construção de práticas educativas

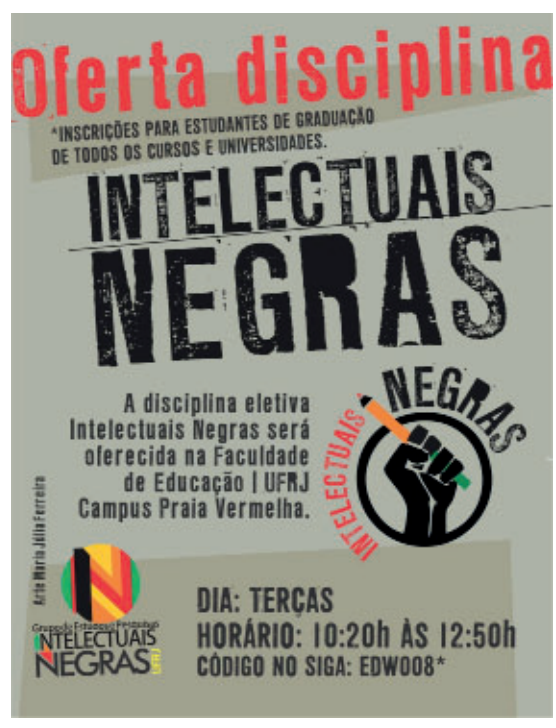

que tratam escrita e oralidade em perspectiva horizontal, assim como a priorização da leitura de autoras negras, a valorização da escrita de estudantes e da reconstituição de seus trajetos familiares representam formas de produção de conhecimento autônomo, com grande potencial de impacto nas nossas comunidades de origem.

Figura 1. Folder de divulgação da inscrição na disciplina Fonte: Acervo do Grupo de Estudos e Pesquisas Intelectuais Negras UFRJ.

\#PraTodoMundoVer A imagem mostra uma propaganda da oferta da disciplina Intelectuais Negras. O texto informa que estudantes de graduação de todos os cursos e universidades podem se inscrever e que as aulas acontecerão às terçasfeiras, das 10 às $12 \mathrm{~h}$, no Campus da Praia Vermelha. Além da logo do Grupo, a sigla IN em traço grosso nas cores vermelho, coral, preto, amarelo, verde, há também o símbolo de um punho cerrado segurando um lápis envolto em círculo. Do lado de fora deste círculo lê-se intelectuais negras. 
Tanto na disciplina como no projeto de extensão universitária Intelectuais Negras Diálogos temos discutido temas cruciais como a importância dos registros escritos, educação com afeto, solidão, as relações entre ciência e ativismo, o papel de professoras da educação básica na reeducação das relações raciais, as estratégias para descolonização dos currículos acadêmicos, a importância do conceito de lugar de fala (Facebook). Com esse esforço, além de sustentar uma agenda acadêmica deslocada do pensamento hegemônico, também assumimos o compromisso de combater o apagamento de intelectuais negras, pensadoras que deixaram contribuições fundamentais para a luta por democracia e justiça social. Entre elas, Azoilda Loretto da Trindade, Beatriz Nascimento, Carolina Maria de Jesus, Lélia Gonzalez, Luiza Bairros. ' Em atenção à preocupação do grupo com metodologias que articulam diferentes linguagens, tivemos a oportunidade de trabalhar o pensamento dessas autoras por meio de arte, cinema, dança, história, literatura, música, entre outras áreas, fazendo com que muitas mulheres se repactuassem ou passassem a se identificar com a carreira acadêmica. Considerando os depoimentos de estudantes, muitas vezes, essa repactuação também foi proporcionada pelo fato de terem tido pela primeira vez a oportunidade de terem uma professora negra. Mas isso é matéria para outro texto, dadas as ambiguidades de força e vulnerabilidade que este lugar da "docente negra" gera (Joselina SILVA, 2010).

Ainda sobre o "criar nossas próprias estruturas", outro exemplo reside na criação do curso de graduação Intelectuais Negras: escritas de si, saberes transgressores e práticas educativas de mulheres negras. Eletiva presente na grade curricular da Faculdade de Educação da UFRJ, a disciplina baseia-se em metodologias inovadoras, tecidas por meio da articulação entre saberes acadêmicos e de movimentos sociais. Em uma lista extensa, destaco o Ateliê Biográfico Intelectuais Negras.

Baseado na perspectiva da "comunidade de aprendizado" (bell books), o método consiste em dividir a turma em grupos que, após uma pesquisa orientada, definem uma intelectual negra para sua autonomeação. Em quatro anos, por meio dessa prática, tornou-se possível que as turmas conhecessem a história e o pensamento de quarenta intelectuais negras, todas reunidas no portal da disciplina, onde também é possível saber mais sobre a história do curso e do nosso plano de trabalho (site da disciplina). Esse reconhecimento do trabalho mental de mulheres de diferentes áreas por parte de estudantes fortalece nossa aposta na difusão de respostas mais plurais e democráticas para a seguinte pergunta: "o que é ser intelectual?". Tal aposta relacionase às discussões promovidas por pensadoras como Grada Kilomba (2016) acerca dos sentidos de ciência em disputa.

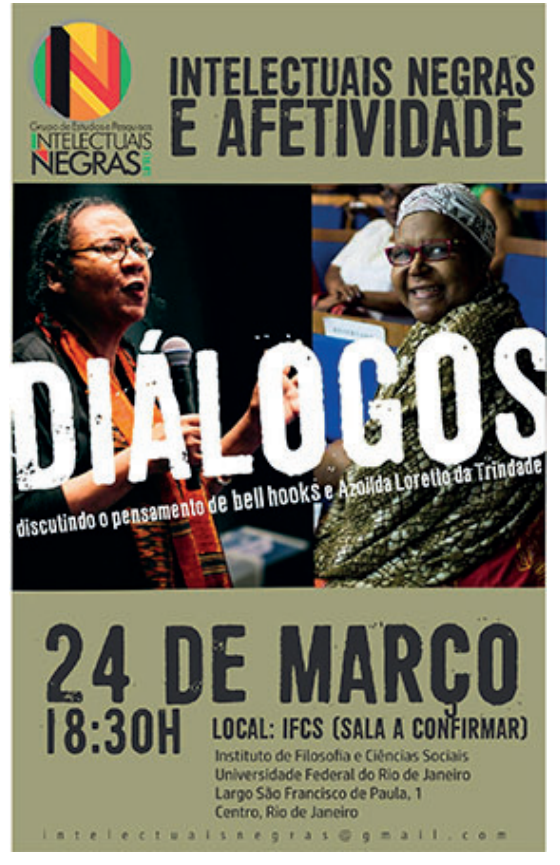

Figura 2. Folder de divulgação de evento relacionado ao projeto de extensão do Grupo

Fonte: Acervo do Grupo de Estudos e Pesquisas Intelectuais Negras UFRJ.

\#PraTodoMundoVer A imagem refere-se à divulgação do encontro Intelectuais Negras Diálogos, voltado à discussão do pensamento de intelectuais negras. A escritora afro-americana bell hooks e a psicóloga Azoilda Loretto da Trindade, cujos textos serão debatidos, são retratadas por meio de fotos acompanhadas de informações sobre o encontro, tais quais: data (24 de março de 2018), horário (18h30min), local (Instituto de Filosofia e Ciências Sociais da UFRJ).

Em termos de uma agenda de pesquisa individual, a construção de categorias de análises inspiradas pelos diálogos com a literatura, como, por exemplo, as ideias de "escrevivência acadêmica", "ciência localizada", "história transgressora", fazem-se presentes tanto em artigos, livros, capítulos, prefácios de obras, entrevistas como em conteúdos produzidos na imprensa e nas redes sociais, em especial, Nexo Jornal e Instagram, este último com expressiva participação de mulheres negras como seguidoras.

Uma das inovações ao alcance de mulheres negras que se autodefinem como intelectuais passa por usar experiências de vida para desafiar os lugares de confinamento aos quais estamos sujeitas. Assim, por meio do reconhecimento da "importância epistêmica da identidade" (Djamila RIBEIRO, 2017), a última seção abordará o papel que mulheres negras que se dedicam

'As intelectuais negras trabalhadas, assim como ementa, bibliografia e métodos desenvolvidos, estão disponíveis no portal da disciplina. 
à intelectualidade pública possuem na construção de conhecimentos autodefinidos que desestabilizam a "colonialidade de gênero" e a "Outridade" (Ochy CURIEL, 201 1; María LUGONES, 2011).

Dentro de uma perspectiva de "narrativa na primeira pessoa", minha própria trajetória enquanto acadêmica revela negociações internas que temos de fazer entre o nosso eu e as imagens controladas que nos são impostas na condição de "outra". A autoidentificação como intelectual negra. O engajamento na construção de uma agenda de trabalho relacionada ao autocuidado. A produção de narrativas acerca dos desafios de conciliar maternidade e trabalho acadêmico. O compartilhamento de rotinas de alimentação saudável e da prática de atividades físicas como a dança e o surf. A dedicação à meditação e ao Yoga. Todos esses movimentos dizem respeito a conteúdos que desestabilizam a epistemologia dominante da mulher negra como nascida e criada para servir, reposicionando-a como sujeita política. Nos meus próprios termos, são formas de afirmar: "você pode substituir mulheres negras como objeto de estudo por mulheres negras contando a sua própria história".

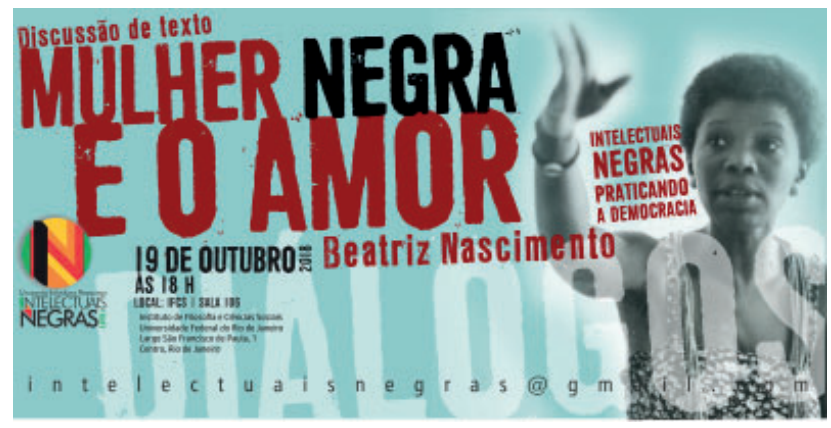

Figura 3. Folder de divulgação do Grupo de evento relacionado ao projeto de extensão do Grupo

Fonte: Acervo do Grupo de Estudos e Pesquisas Intelectuais Negras UFRJ.

\#PraTodoMundoVer A imagem referente a mais uma divulgação do encontro Intelectuais Negras Diálogos mostra a historiadora e ativista dos movimentos sociais negros Beatriz Nascimento. Em letras capslock há "Discussão de texto Mulher negra e o amor", artigo escolhido para o debate. Além disso, constam informações sobre dia (19 de outubro), horário (18h), local (Instituto de Filosofia e Ciências Sociais da UFRJ). Por se tratar de um evento realizado próximo às eleições presidenciais, na altura do rosto de Beatriz aparece a frase "Intelectuais Negras praticando a democracia". Constam também a logo e o email do grupo: intelectuaisnegras@gmail.com.

\section{\#dotorainspiração: intelectualidade pública e ativismo virtual}

Dia 08 de abril de 2018. Acordei cedo. Peguei o metrô. Da Tijuca para a zona sul. Chegando em Ipanema, parei em uma banca de jornal. Comprei o jornal O Globo. Caminhei até a praia. Sentei em um banco. De frente para o mar, abri o periódico em busca da revista. Com ela em mãos, comecei a folheá-la. Em dado momento, deparei-me com minha imagem. Ocupando toda a página, lá estava eu, vestida de linho e seda brancos. Com sorriso escancarado, em pé, de braços cruzados, ostentando um lindo colar de búzios. O título da matéria, curto e objetivo: 'Dotora Inspiração'. Estávamos em um domingo. Dia do meu aniversário de 39 anos.

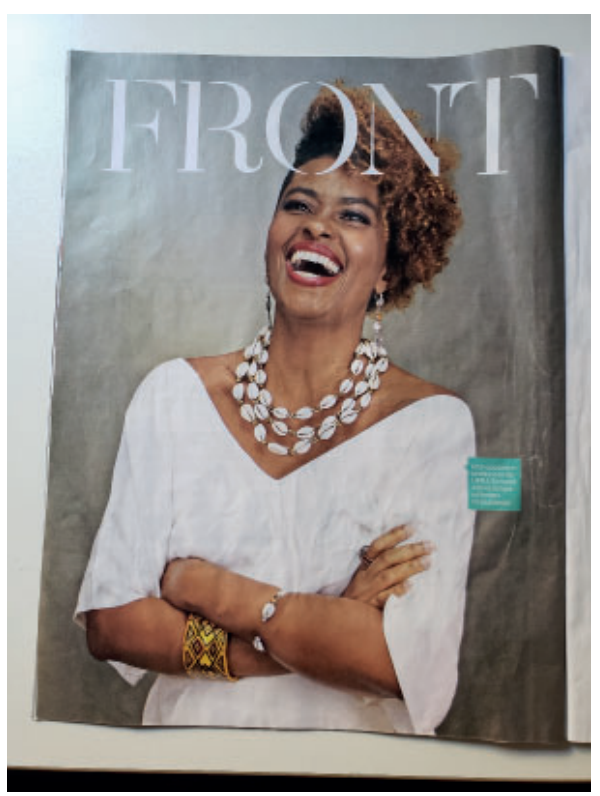

Figura 4. FRONT: 'Dotora Inspiração' Fonte: O Globo. Caderno Ela, 08/04/2018.

\#PraTodoMundoVer A imagem é composta por uma fotografia de página inteira de Giovana Xavier na sessão Front, do Caderno Ela, suplemento do jornal O Globo. Vestida de branco, braços cruzados, usando pulseira amarela, bracelete e colar de búzios, a professora está em pé, de braços cruzados, gargalhando. Na página à direita, a reprodução da entrevista intitulada "Dotora' Inspiração" e assinada pelo jornalista Eduardo Vanini (2018).

Li a matéria, escrita de forma extremamente cuidadosa. $^{2}$ Feliz de ter a palavra Front estampada em minha testa, levantei do banco, abracei a revista. Olhei para o céu. Lembrei todo o trabalho que minha mãe e minha avó realizaram ao longo de suas vidas. Agradeci-as. Pensei em Peri. No quanto aprendo como sua mãe. Lembrei que, mais tarde, cantaríamos parabéns e cortaríamos o bolo juntos. Desci para areia. Peguei minha prancha. Caminhei em direção ao mar. Na volta do surf, tornei-me visível. Não que não o fosse antes, mas dessa vez estava sendo vista sob novas lentes. Como alguém que trilhou um "caminho sem volta. Da faculdade foi para o mestrado; do mestrado para o doutorado sanduíche com

${ }^{2}$ Agradeço ao jornalista Eduardo Vanini por disponibilizar a cópia digital da entrevista. 
uma imersão na New York University; e daí para o pós-doutorado e a conquista de uma cadeira no corpo docente da UFRJ". Essas credenciais, narradas no jornal de maior circulação do país, contribuíram para legitimar a trajetória intelectual de uma mulher negra. Uma doutora que, do front, alertava o público: "O que peço é que as mulheres negras sejam mais escutadas, afinal a gente tem voz, o que não temos são ouvidos".

Carregada de subjetividades, essa história que protagonizei relaciona-se à importância de partirmos de novos pontos de vista para escrita das nossas histórias. Ela se insere no desafio de criar autodefinições afirmativas em estruturas que alimentam imagens controladas sobre nossos corpos e mentes. Cada vez mais, mulheres negras que assumem o lugar de intelectuais públicas são convocadas a desenvolver estratégias que conciliem suas autorrepresentações com o controle de imagens a que estamos sujeitas. Diversos exemplos, sem hierarquias de importância, são convidativos para pensarmos a respeito. Citemos dois que geraram bastantes debates em 2018: a candidatura de Conceição Evaristo para uma cadeira na Academia Brasileira de Letras e a participação de Djamila Ribeiro na bancada do programa Amor \& Sexo. No primeiro exemplo, o fato de uma escritora, com formação acadêmica de doutora, proveniente das classes trabalhadoras, candidatar-se a uma vaga na Academia Brasileira de Letras culminou em discussões sobre as relações entre gênero, raça e classe essenciais à construção de novas epistemologias. Entre elas, o que é ser intelectual?; quem tem o direito de ser reconhecido como "imortal" devido à sua obra? Em síntese, retomando minha própria indagação: "quais são os critérios para ser "imortalizada" em um país assentado na distribuição desigual de conhecimento como algo natural?" (XAVIER, 2018). Já no segundo, a participação de Djamila Ribeiro em um programa televisivo na maior emissora do país, compartilhando seus pontos de vista sobre bem-estar, maternidade, política, relacionamentos afetivos, entre outros, desembocou em discussões sobre o papel da representatividade na mídia para que mulheres negras possam ser reconhecidas como pessoas que podem, sabem e querem falar sobre todas as coisas. Essa constatação relaciona-se ao principal lema da organização Marcha Nacional das Mulheres Negras: "Pelo bem-viver".

A experiência de participar de programas televisivos sempre gera muitos debates, dividindo as opiniões, principalmente entre pessoas negras. Em 2018, participei, em duas ocasiões, do Encontro. Apresentado pela jornalista Fátima Bernardes, o programa é transmitido na parte da manhã, às $11 \mathrm{~h}$. Considerando a influência que a televisão possui na formação de opinião da população e levando em conta que a maioria dos lares brasileiros é gerida por mulheres (donas de casa ou trabalhadoras domésticas), aparecer na tela veiculando conteúdos relacionados ao combate ao machismo, assim como ao papel das mulheres na ciência, é um trabalho intelectual relevante, que atinge milhões de pessoas. Na primeira ida ao programa, em menos de vinte e quatro horas ganhei mais de mil seguidoras no Instagram, o que, obviamente, também é assustador se pararmos para pensar no papel que a grande mídia desempenha na vida política do país. Para fugirmos da falsa polêmica participar ou não, acredito ser importante discutirmos os métodos de nossa participação, assim como observar as maneiras pelas quais conseguimos penetrar nessas estruturas. Uma penetração estratégica, sem abrir mão do nosso conhecimento autodefinido.

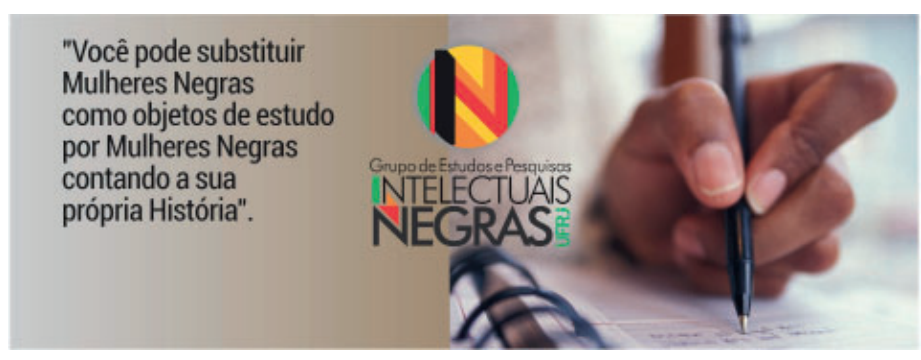

Figura 5. Folder de divulgação do Grupo

Fonte: Acervo do Grupo de Estudos e Pesquisas Intelectuais Negras UFRJ.

\#PraTodoMundoVer A imagem contém a frase "Você pode substituir mulheres negras como objeto de estudo por mulheres negras contando a sua própria história". Trata-se de um slogan do Grupo Intelectuais Negras UFRJ, que também aparece representado por sua logo, que está ao lado da imagem de uma mão de uma mulher negra segurando uma caneta e escrevendo no caderno.

Em geral, esses convites derivam do acompanhamento dos conteúdos que produzimos em redes sociais. Nesse sentido, quando somos convidadas já existe uma expectativa do que teremos a dizer. É improvável minha participação em qualquer programa para falar contra ações afirmativas, defender a redução da maioridade penal, naturalizar o feminicídio e outras tantas violências que nossos televisores transmitem diariamente. Inúmeras vezes, nossa participação representa a garantia de explicitação de conteúdos que colocarão as pessoas para pensar sob novos pontos de vista. Além disso, ela também pode se desdobrar em um lugar político importante: o de influenciadoras digitais acessadas para indicação de pautas, sugestão de convidadas e outras ações que contribuem para combater a sub-representatividade a que estamos sujeitas nos meios de comunicação. 
Como acadêmica, sei que a universidade é um espaço de acesso restrito. Assim, assegurar que os saberes científicos produzidos por mulheres negras sejam reconfigurados e discutidos com público mais amplo é também uma forma de dar retorno à nossa comunidade. É sempre impressionante a quantidade de mensagens que recebo durante e depois dessas aparições. $O$ teor das conversas também revela muito sobre o poder de nossas imagens. Nessas ocasiões, por exemplo, costumo receber textos de mulheres trabalhadoras domésticas relatando terem mostrado minha fotografia para estimular suas filhas a estudarem para Exame Nacional do Ensino Médio, em busca de uma vaga na universidade pública.

Nesse caso, independente da narrativa, minha presença - materializada no corpo, na roupa, nos gestos, nas titulações - torna-se o principal conteúdo. Um conteúdo que inspira muitas pessoas a sonharem com lugares em que são desautorizadas para estarem ou desejarem. Assim, logo após minha primeira ida ao referido programa, publiquei o seguinte comentário, ilustrado por uma foto com a apresentadora:

[...] Já foi pauta das minhas aulas de Prática de Ensino de História Transgressora participar ou não de programas de grande mídia. Eu mesma tenho muitassss ressalvas, mas o fato é que \#Encontro tem levado pautas importantes para a televisão. Isso é feito em um horário chave no qual muitas mães, donas de casa, empregadas domésticas estão trabalhando com a tv ligada. Mover o mundo passa por desenvolver sabedoria para estar - atenta e plena - em todos os espaços. E, na moral, galera, a Fátima e a produção têm uma ótima escuta, dentro de limites que tornam possíveis levarmos novos olhares para velhos problemas. Hoje foram dois: a precariedade da educação e o problema da moradia no Brasil. Eu torço e trabalho para que estas pautas de grande relevância ( 1 em cada sete mulheres de 40 anos TERÃO câncer de mama, aprendi hoje!) não fiquem restritas aos programas de "entretenimento" do pré-almoço. $\mathrm{E}$, após a missão cumprida, fico grata por ocupar um lugar de fama na condição de uma mulher negra professora universitária que trabalha para difundir a ciência no nosso país. Obrigada @ fatimabernardes e equipe pelo convite! (XAVIER, 03/09/2018).

Assim, voltando ao tempo, encerro o texto em 2017, com minha resposta à pergunta feita pelo editor José Orenstein em entrevista ao Nexo Jornal, onde, no ano seguinte, tornei-me colunista:

\begin{abstract}
$[\ldots]$
JO: Como você chegou a essa carreira? O que te motiva? Por que você a escolheu?

GX: Esta é uma pergunta difícil de responder porque ela é resultado de muitas histórias. Fui criada por uma família de mulheres negras que acreditaram e colocaram em prática o poder da educação como instrumento de liberdade e ascensão social. Minha mãe, Sonia Regina (ancestral), foi a primeira da família a cursar a universidade. Isso revela uma característica típica de famílias negras: o investimento na formação de um indivíduo (geralmente o mais novo) como projeto de liberdade e transformação coletivo. Essa marca, sempre presente nas histórias que hoje escuto meus estudantes pretos contarem, é um saber que temos aprimorado como comunidade negra e que evidencia os limites da meritocracia como conceito que dê conta de explicar as oportunidades desiguais que recebemos a depender de quem somos em termos raciais, de gênero, de classe, sexualidade. Então posso dizer que o fato de ter sido socializada em um matriarcado que acreditou que eu poderia ser quem eu quisesse, estimulando-me a ler, escrever, aprender outros idiomas, motivou-me a transgredir, indo além do destino esperado para as meninas negras do Brasil: o trabalho doméstico, ramo em que inclusive trabalhei por um tempo, quando fui arrumadeira de pousada na llha Grande na adolescência. Meu primeiro trabalho foi aos 11 anos, entregando panfletos "Vendo Ouro" na ponte do subúrbio do Méier, no Rio de Janeiro, onde fui criada. Até hoje tenho pavor de receber esses papéis, por saber das violências e perversidades que rodeiam a juventude que desde cedo tem de se virar, encarando a rua como local de trabalho. Essas experiências de inserção no mercado informal somadas à oportunidade de ter estudado em uma escola branca de classe média me geraram um ponto de vista denso sobre como estar em dois mundos e, do interior deles, criar o meu próprio. Acho que esta tem sido minha busca pelo "caminho de casa", para usar a expressão marcante da escritora ganense Yaa Gyasi. Na linha "força, foco e fé", pergunto-me diariamente: como, na condição de mulheres negras, podemos e devemos reivindicar a intelectualidade, construindo um universo para chamar de nosso, dentro e fora da academia? A história, enquanto matéria dedicada à interpretação de processos sociais e à construção de identidades individuais e coletivas, oferece ferramentas para responder à minha pergunta. Entretanto, estamos falando ao mesmo tempo de uma disciplina que contradiz minha própria motivação se considerarmos que ela foi criada a partir de uma lógica branca, masculina e eurocêntrica. As ferramentas da história e da academia como um todo precisam ser empretecidas na forma de uma ciência para o negro, conforme sinalizado pelo sociólogo Eduardo de Oliveira e Oliveira e pela historiadora Beatriz Nascimento nos anos 1980. Entendendo-me como continuidade, essa é minha missão, definida por meus ancestrais. É isso que me motiva a seguir fazendo ciência, diariamente (XAVIER, 2017).
\end{abstract}

Semelhanças não são meras coincidências.

No FRONT, minhas orelhas carregavam o brinco de Ewá, a orixá senhora das possibilidades. 


\section{Referências}

ABREU, Martha; MATTOS, Hebe (Dir. Acadêmica); FERNANDES, Guilherme; CASTRO, Isabel (Dir.). "Memórias do Cativeiro". In: Coletânea LABHOI UFF Passados Presentes, Niterói, 2007. Disponível em https://www.youtube.com/watch?v=JEw4k8Wpofw.

BOSCO, Francisco. A vítima tem sempre razão? Lutas identitárias e o novo espaço público brasileiro. Rio de Janeiro: Todavia, 2017.

COLLINS, Patricia Hill. "O poder da auto-definição". In: COLLINS, Patricia Hill. Black feminist thought: knowledge, consciousness, and the politics of empowerment. Nova York/Londres: Routledge, 1990. p. 01-35. (Tradução de Natália Luchini. Seminário "Teoria Feminista", Cebrap, 2013)

COLLINS, Patricia Hill. Pensamento feminista negro. São Paulo: Boitempo, 2019.

CRENSHAW, Kimberlé. "Mapping the Margins: Intersectionality, Identity Politics, and Violence against Women of Color". Stanford Law Review, Standford, v. 43, n. 6, p. 1241-1299, jul. 1991. Disponível em https://www. istor.org/stable/1229039?seq=1 \#page scan tab contents. Acesso em 17/01/2019.

CURIEL, Ochy. "El régimen heterosexual y la nación. Aportes del lesbianismo feminista a la Antropología". La Manzana de la Discordia, Barcelona, v. 6, n. 2, p. 25-46, 2011. Disponível em https://www.scribd.com/doc/253530888/Karina-Bidaseca-y-Vanesa-Vazquez-Laba-CompsFeminismos-y-Poscolonialidad-Descolonizando-El-Feminismo-Desde-y-en-America-Latina. Acesso em 30/01/2018.

HARAWAY, Donna. "Saberes localizados: a questão da ciência para o feminismo e o privilégio da perspectiva parcial". Cadernos Pagu, Campinas, v. 5, p. 07-41, 1995. Disponível em http://www. bibliotecadigital.unicamp.br/document/?down=51046. Acesso em 12/09/2018.

hooks, bell. "Intelectuais Negras". Revista Estudos Feministas, Rio de Janeiro, v. 3, n. 2, p. 464478, 1995. (Dossiê Mulheres Negras) Disponível em https://periodicos.ufsc.br/index.php/ref/article/ view/16465/15035. Acesso em 08/11/2019.

KILOMBA, Grada. "Descolonizando o conhecimento: uma palestra performance". Mostra Internacional de Teatro de São Paulo, 06/03/2016. Disponível em http://www.goethe.de/mmol priv/15259710-STANDARD.pdf. Acesso em 12/09/2018.

LIMA, Betina Stefanello; BRAGA, Maria Lucia de Santana; TAVARES, Isabel. "Participação das mulheres nas ciências e tecnologias: entre espaços ocupados e lacunas". Revista Gênero, Niterói, v. 16, n. 1 ، p. 11-31, 2015. Disponível em https://periodicos.uff.br/revistagenero/article/view/31222/1831 1.

LUGONES, María. "Hacia um feminismo descolonial". La Manzana de la Discordia, Barcelona, v. 6, n. 2, p. 105-119, jul./dez. 2011. Disponível em https://periodicos.ufsc.br/index.php/ref/article/ view/36755. Acesso em 29/07/2018.

PARMAR, Pratibha. "Feminismo negro: la política como articulación". In: JABARDO, Mercedes (Ed.) Feminismos Negros: Una Antología. Madrid: Traficantes de Sueños, 2012. p. 245-267. Disponíve em https://www.traficantes, net/sites/default/files/pdfs/Feminismos\%20negros-TdS.pdf. Acesso em $30 / 01 / 2018$

MURRAY, Pauli. Song in a Weary Throat: An American Pilgrimage. New York: Harper and Row, 1987

RIBEIRO, Djamila. O que é lugar de fala? Belo Horizonte: Letramento, 2017.

SILVA, Joselina. "Doutoras Negras: o que dizem os indicadores oficiais". Perspectiva, Florianópolis v. 28, n. 1, p. 19-36, jan./jun. 2010. Disponível em https://periodicos.ufsc. br/index.php/perspectiva/ article/view/2175-795X.2010v28n1p19/17811. Acesso em 17/01/2019.

VANINI, Eduardo. "FRONT; 'Dotora' Inspiração". O Globo, 08/04/2018.

XAVIER, Giovana. "Conceição Evaristo: abrindo novos parágrafos na história do Brasil". Nexo Jornal, São Paulo, 14/05/2018. Disponível em https://www.nexojornal.com.br/colunistas/2018/ConceiçãoEvaristo-abrindo-novos-parágrafos-na-história-do-Brasil. Acesso em 10/10/2019.

XAVIER, Giovana. "O dia em que Rui Barbosa sorriu (ou chorou?)". Medium @pretadotora 09/06/2014. Disponível em https://medium.com/pretadotora/o-dia-em-que-rui-barbosa-sorriu-ouchorou-f819a3864533?source=rss------1. Acesso em 07/1 1/2019. 
XAVIER, Giovana. "Como me tornei historiadora e a vida entre livros e sala de aula". Nexo Jornal, São Paulo, 16/10/2017. Disponível em https://www.nexojornal.com.br/profissoes/2017/10/16/Comome-tornei-historiadora.-E-a-vida-entre-livros-e-salas-de-aula. Acesso em 07/1 1/2019.

Giovana Xavier (giovanaxc@gmail.com) é doutora em História Social, professora da UFRJ e coordenadora do Grupo Intelectuais Negras UFRJ, líder apoiada pelo Programa de Aceleração do Desenvolvimento de Lideranças Femininas Negras Marielle Franco - Fundo Baobá para Equidade Racial. É autora dos livros Você pode substituir Mulheres Negras como objeto de estudos por Mulheres Negras contando sua própria história e Maria de Lourdes Vale do Nascimento: uma intelectual negra do pós-abolição. Como ativista intelectual, assina a plataforma @pretadotora, na qual discute temas como autocuidado, maternidade, yoga, espiritualidade e trabalho acadêmico sob o ponto de vista de mulheres negras.

\section{COMO CITAR ESSE ARTIGO DE ACORDO COM AS NORMAS DA REVISTA}

XAVIER, Giovana. "Como me tornei \#dotorainspiração e o brinco de Ewá". Revista Estudos Feministas, Florianópolis, v. 29, n. 1, e61683, 2021.

\section{CONTRIBUIÇĀO DE AUTORIA}

Não se aplica.

\section{FINANCIAMENTO}

Não se aplica.

\section{CONSENTIMENTO DE USO DE IMAGEM}

Não se aplica.

\section{APROVAÇĀO DE COMITÊ DE ÉTICA EM PESQUISA}

Não se aplica.

\section{CONFLITO DE INTERESSES}

Não se aplica.

\section{LICENÇA DE USO}

Este artigo está licenciado sob a Licença Creative Commons CC-BY 4.0 International. Com essa licença você pode compartilhar, adaptar, criar para qualquer fim, desde que atribua a autoria da obra.

\section{HISTÓRICO}

Recebido em 21/02/2019

Reapresentado em 25/10/2019

Reapresentado em 07/1 1/2019

Reapresentado em 23/01/2020

Aprovado em 01/04/2020 